\title{
Transformative Mediation: In Search of a Theory of Practice
}

LISA P. GAYNIER

Transformative mediation has taken hold in certain mediation circles, generated consternation in others, and been the topic of vigorous debate at some professional mediators' conferences. This article argues that a solid grounding in Gestalt-based theory allows the mediator to approach disputants with intentional support for expanding the ground between them, thus supporting mutual recognition and empowerment.

T thas long been an adage in mediation circles that the mediator "controls" the process and disputants control the outcome, as compared to our judicial system, in which disputants control neither. Although it is true that many mediators control the process quite literally, true mediation calls for the mediator to be a steward, not a dictator of the process. Thus it is with interest and concern that I have followed the work of Robert Baruch Bush and Joseph Folger as they and their colleagues develop transformative mediation.

They do the field of mediation a service by shaking up the status quo. Unfortunately, in the almost ten years since publication of The Promise of Mediation we have not seen a rigorous research response, and without sufficient assessment at the empirical level it is difficult to measure the effects of the transformative approach on practice. It is clear however, that Bush and Folger have provoked as much controversy as they have evoked, not so much because of what they have said but how they have said it.

This article (1) surveys developments in the field of mediation and mediation research since Bush and Folger's 1994 publication , (2) addresses fundamental weaknesses in their arguments, and (3) proposes a theoretical basis for the transformative approach to mediation. 


\section{Survey of Recent Past and Continuing Trends}

Bush and Folger (1994) questioned two basic assumptions of mediation: (1) that the objectives of mediation are settlement and problem solving, and (2) that mediators control the process. Their ideology drives a moral growth imperative and a belief that moral growth and "settlement" are mutually exclusive: "The case for the transformative approach rests on whether people believe in the values that drive it" (Bush and Folger, 1994, p. 229). To achieve this goal of transformation, Bush and Folger advocate another approach for the mediator: support empowerment and recognition.

Their recent work has concentrated on how the experience of conflict "de-skills" people_ it makes them weak and self-absorbed, and it alienates them from both self and other (Bush and Folger, 1994). In recent years, they have drawn on conflict theory as the basis for understanding their approach (see Bush and Pope, 2002, for more on their theory about conflict). At the same time, Bush, Folger, Della Noce, Antes, and others rightly challenge the increasing domination and misuse of mediation by the courts and the larger legal community. Many practitioners in community mediation share this concern. In fact, it is a more serious challenge to the values and practice of mediation than is the debate over transformative mediation (visit the National Association for community Mediation's Website, www.nafcm.org, for the policy position it has taken on the Uniform Mediation Act).

Bush and Folger have indicated in several recent articles that transformative mediation cannot and should not be melded with other kinds of mediation (Folger and Bush, 1996b). It is an unfortunate position because the stated theoretical basis for the practice of transformative mediation is weak and could benefit from cross-pollination.

Transformative mediation gained wider recognition when the U.S. Postal Service (USPS) embraced it in 1996 after a pilot in 1994 (Hallberlin, 2001). In 2001, Nabatchi and Bingham's study confirmed that REDRESS mediators were adhering to transformative mediation practice, the premise being that the success of REDRESS could be attributed to transformative mediation rather than mediation in general. However, the REDRESS studies have not yet addressed whether transformative mediation actually resulted in the stated goal of an improved workplace culture at the USPS (Hallberlin, 2001).

As a former survey manager at the University of Michigan's Institute for Social Research, I am concerned about the research methodology of some 
of the REDRESS studies. The research published in 2001 by Antes, Folger, and Della Noce relied on secondhand reporting by REDRESS observers, not the disputants themselves. There was no use of primary sources (actual disputants). The researchers said this was due to confidentiality issues, but there are methods of surveying disputants without compromising confidentiality. The use of third-person accounts compromises the credibility of the study intent. Second, in a survey of REDRESS mediators conducted by Bingham in 2000-01, thirteen of twenty-eight question-and-response options in one section were biased in favor of transformative mediation. As an example, question number three was: "The Mediator asked us what we thought should be done." There were three response options: "empowerment/recognition," "directive/evaluative," or "neither." Additionally, the survey was confusing because the questions were written for disputants but was actually administered to mediators. It may have been an oversight, but lapses in quality control or good judgment compromise study results, particularly conclusions drawn from the data.

\section{Opponents, Critics, and Skeptics: Different Perspectives}

In a keynote address at the 2002 Southern California Mediation Association conference, Folger bemoaned opposition or resistance to their team's work on two levels. He referred to pressure that had been brought to bear upon him to "make peace with the field" (Folger, 2002). He even stated that physical threats against his safety have been made! "As a field, we do not do conflict resolution well when it comes to our own issues," he added (Folger, 2002).

In another symposium lecture, Folger addressed how ideology shapes social science research. He quoted Thomas Kuhn, in The Structure of Scientific Revolutions, to demonstrate what he and his colleagues are up against: "when prevailing research is in place, attempts at raising alternative research questions are often publicly debunked, deligitimized [sic], or even ridiculed" (Folger, 2002, p. 386). In a keynote address to the Iowa Association of Dispute Resolution (1998), Dorothy Della Noce addressed the conflict and urged attendees to embrace the "opportunity . . . to move toward the conflict." These transformative mediation scholars perceive quite severe opposition to their work.

In contrast, Levin states that the evaluative mediator "tends not [italics are mine] to be critical of facilitative mediation. ... In the main, however, criticism runs in the opposite direction, with the facilitative mediator 
rejecting a role for evaluation in mediation" (Levin, 2001, p. 267). Other skeptics of transformative mediation have had similar experiences.

Murray Levin and others have addressed the issue of mediation process pluralism, advocating for broad rather than narrow definitions of mediation and the related need for consumers to have choices (Levin, 2001). As for cross-pollination, Michael Williams and Kelly Doyle argued that hybrids are possible, and in fact preferable to transformative mediation's claims of purity (Williams, 1996; Doyle, 2002). Williams also believes that since disputants come to mediation for help in resolving problems, to push the mediator's objective is unethical (Williams, 1996).

In 1999, Seul published a highly thoughtful critique of Bush and Folger's view that the primary purpose of mediation is human moral development. Seul faults Bush and Folger for not offering a comprehensive theory of human development and for ignoring the ones that do exist. Using the model of Robert Kegan (1982), a constructive-developmental psychologist, he critiques Bush and Folger's work (Seul, 1999). The gist of Kegan's argument in his book In Over Our Heads is that, with the exception of the organizational theorist William Torbert, "None of the psychological approaches to conflict resolution-not the efforts of pioneering social psychologists, nor the more recent work of the family therapists or the organization developmentalists - attends to the individual's development of consciousness. As a result, none of these theorist-practitioners is in a position to consider the demands their respective curricula make on mental capacity or to assess a person's readiness to engage in their designs."

Seul makes some cogent arguments with which Bush, Folger, and their colleagues would do well to engage.

Terri Kelly suggests that transformative mediation has "evolved as a result of observations rather than systematic analysis of theoretical concepts leading to applications" (Kelly, 2000, p. 1). She suggests there are existing theories that premise transformative mediation and points out assumptions about human behavior implicit in these theories. Despite her critique, Kelly is sympathetic to transformative mediation. Others simply do not agree with Bush and Folger that mediation should be so narrowly circumscribed; Lande does a nice job of articulating the various arguments (Lande, 1997).

There are many practitioners of transformative mediation who believe it is a good start but that it does not fully support them in their work. The reason lies with Bush and Folger's narrow dependence on empowerment and recognition, ignoring such other powerful influences as resistance, 
a disputant's own competing (or conflicting) interests, and a mediator's lack of awareness of herself as a player in the dynamic.

If one did not know better, one would think Bush and Folger based their criticism of mediation on the way it is practiced around the courthouse (by lawyers, judges, and others); but they criticize the practice of mediation in community, family, and other settings, where empowerment has a long history as well.

Others are put off by Bush and Folger's claim to the word transformative. They are not the first to use the term in reference to mediation and its potential impact on communities. Paul Wahrhaftig, president of Conflict Resolution Center International and a REDRESS mediator, makes several points (personal interview, April 2003). One is that there seems to be confusion between being transformative and being nondirective (passive). Experienced mediators know that transformation does not always follow from the so-called nondirective approach, and that "transformation" can and often does occur as a result of a more active mediator stance (which Bush and Folger label as directive).

Timothy Hedeen, a community mediator and conflict management educator, maintains both an appreciation for and concerns about the transformative approach: "Transformative mediation has served us well in re-emphasizing the goals of empowerment and recognition, yet I've been troubled by the way it's presented as some sort of orthodoxy" (personal interview, April 2003). Hedeen finds problematic both the presumption of universality and the proclaimed exclusivity of transformative practice: "That transformative practice cannot be co-mingled with other approaches, and that mediators are fully 'transformative' or they're not at all, these assertions strike me as contrary to mediation's premise of recognizing multiple realities and responding differently to various contexts" (personal interview, April 2003).

Robert Benjamin notes that although Bush and Folger have backed away from moral growth as an objective, their "ideology still demands adherence to the primacy of process over outcome. They will not even tolerate the notion of balancing the two" (Benjamin, personal interview, March-April 2003). Process trumps outcome because of Bush and Folger's bias in favor of experiencing the opportunity of moral growth.

In a survey of the literature prepared for this article, it was dismaying to see what was missing from the bibliographies of Bush, Folger, and their colleagues. They would not have had to look far for scholarship to support their theories. Their most recent work (Bush, 2002; Folger, 2002) appears 
to be making some amends in this regard, but there is much more to be done. It may be true, as they assert, that mediation is a field that has imported theories and not developed its own, but I disagree that the theories "inherently become somewhat distorted when imported and adapted to the goals of third party intervention" (Della Noce, Bush, and Folger, 2002, p. 40). Therapy and most organizational interventions are all about intervening with people in conflict. Why should this related scholarship not have some relevance for mediators?

\section{Theory of Practice}

Amid all the interest and advocacy for transformative mediation, and even with Bingham's research on the results of transformative mediation, few people have really examined the theories of practice behind it. By theory of practice is meant significantly more than Bush and Folger's ideologically based theory of human morality, the relational worldview.

In their book, Bush and Folger criticized all other methods of mediation as focused on settlement or outcome, saying that mediators should not be driving for outcomes, all the while creating their own (the moral growth of their clients). In subsequent articles, they have backed away from the idea of "transforming people's characters," agreeing that "attempting to change or transform the parties would be as directive as attempting to construct settlements for them" (Folger and Bush, 1996, p. 277). They have shifted their stance: mediation has "potential transformative effects" (Folger and Bush, 1996, p. 277; the italics are theirs).

\section{The Problem with Transformative Mediation}

As espoused in The Promise of Mediation, "conflict is first and foremost a potential occasion for growth in two critical and interrelated dimensions of human morality ... strengthening of self" and "reaching beyond self to relate to others" (Bush and Folger, 1994, p. 81). Bush and Folger advocate further that in order to promote moral growth the mediator must focus on "empowerment" and "recognition." Happily, Bush's recent work has downplayed moral growth and focused on supporting party deliberation and perspective taking (Bush, 1999, 2002). Although this shift is welcome, I share Benjamin's concern that moral growth is still very much what drives Bush.

I squirm with discomfort at the moral growth imperative of transformative mediation, but my approach to client work is quite similar to the 
transformative approach as described in their book. So why my discomfort? I believe that Bush and Folger have missed the mark, specifically in four areas:

1. Methodology versus objectives

2. The goal of moral growth and its implications

3. Mediator presence and why it matters

4. The lack of a theory of practice

It is important to separate methodology (process) and objectives (outcomes). Bush and Folger say that objectives drive methodology. Though true as a first step, I submit that approach and objectives are distinct. A con artist uses accepted, even admirable, interpersonal skills to achieve theft. This does not make his intent to steal inherently OK. Nor does his objective (theft) make his methodology intrinsically bad.

Bush and Folger advocate a position that is in serious error: that the objective (intent) of mediation is moral growth, and further that this objective is what dictates method. One may sympathize with their desire to encourage moral growth, but taking such a stance falls into much the same trap as the problem-solving orientation: the values of the mediator trump the clients' own values and needs, and worse, the mediator imposes those values on clients. History has shown that imposition of a moral imperative by one (group) on another has met with limited success and often disastrous results.

More important, it is not necessary for mediators to assume the mantle of responsibility for moral growth. Mediators play an important enough role in mediation without being responsible for others' moral growth. At its most fundamental, the tradition of mediation is based on respect for people's integrity and belief in their capacity to solve their own problems individually and collectively. The methodology Bush and Folger advocate supports this respect, but they undermine it with their moral growth ideology.

Bush and Folger are instinctively reaching for a new paradigm because they have experienced the "magic" that comes from attending to the phenomenological experience of the two people in dispute becoming more fully who they are. It is this experience that empowers and paradoxically allows mutual recognition. Further, it is for this reason that many advocates of transformative mediation have sidestepped the moral growth imperatives 
of transformative mediation while fully embracing the methodology. The methodology works!

What drives the apparent success of transformative mediation is the principle of self-determination within the context of a relational field. The methodology has its own integrity, and moral growth tends to occur especially if it is applied by an impartial intervenor who withholds judgment.

Bush and Folger describe a mediator role that facilitates this magic, but they do not articulate a theoretical construct that explains the "transformation" they have often witnessed. In other words, they lack a theory that explains the practice. In saying it is the objective of moral growth that drives the success of transformative mediation, Bush and Folger propose only an explanation, not a theory of practice. Further, their explanation is incorrect. Their end does not explain the means, and (their recent writings notwithstanding) they still focus on ideology as the basis for their theory.

Theory is more than vision and values (Charbonneau, 2001). A theory is a supposition or an idea that explains a phenomenon. Therefore, when one sees people in conflict converse about it and a positive shift or breakthrough occurs, the mediator should want to know why. What happened to have caused this shift? What is the theory behind one's behavior or presence as a mediator that supports the shift? One's own values are only a starting point. In other words, mediators need a theory of human meaning making and human interaction to guide them as they interact with the disputants. Further, they need to understand the role they play in this human interaction.

\section{Toward a Theoretical Construct}

Transformative mediation methodology as described in Bush and Folger's book is quite similar to techniques used in the therapeutic field and the process consulting approach to organization development (see the "single and double-loop learning" work of Argyris and Schön, 1978; and "freezing and unfreezing" by Lewin, 1948). Schein presents a useful parallel (1987) in describing three models. The first two are the "purchase of information or expertise" model, in which the client diagnoses the problem and purchases services to address the problem; and the "doctorpatient" model, a variant of the "expert" model, in which the intervenor both diagnoses and recommends the remedy. Both are expert approaches to organizational consulting and equate with evaluative mediation. The third Schein calls the "process" model because its central premise is that 
the client "owns the problem" and "continues to own" it through the consulting relationship (pp. 22-35). This can be equated with facilitative, empowerment, and transformative approaches to mediation.

Bush and Folger's focus on empowerment and recognition is a nice start, but they do not go far enough. Human beings seek to make their life experiences coherent and whole. People in conflict remain there until they are able to complete the conflict experience in a manner that allows "psychic" resolution. Empowerment and recognition are parts of the meaning making but do not in and of themselves help disputants finish their experience of the conflict.

Gestalt theory, which arose out of phenomenology, can be helpful. It presents a unifying rubric that not only explains human experience but also yields the "how" - the methodology that informs the knowledge. Gestalt theory has evolved over the last fifty years, encompassing systems theory as it spreads beyond therapeutic uses into organizational behavior and organizational development. This is an important point since there is a long-standing debate about the appropriateness of therapeutic approaches in mediation. Let me be clear: I am not advocating the use of therapy in mediation.

Gestalt theory at its most fundamental is concerned with two things. The first is the present ... raising awareness about the self and one's environment in the moment, the here and now. The past is imbedded in the present moment. The second is the "whole," a rough translation of "Gestalt." We human beings seek to understand our environment in an organized manner. Further, everything that captures our attention is in the context of its background (figure or ground). Significantly, the Gestalt approach is noninterpretative and nonjudgmental, emphasizes personal responsibility, and is holistic.

Whether they realize it or not, Bush and Folger's microfocus on disputants moment by moment is informed by the work of the earliest Gestalt psychologists (summarized in Latner, 2000). Fritz Perls expanded this work and explained that it supported people in creating wholes from unfinished business. For example, in Bush and Folger's landlord-tenant case, the mediator supports the tenant in surfacing her anger at the landlord because she thinks he has reported her to child welfare. In point of fact, she does not know that he actually did, but whether he did or not it is unfinished business she has, and it informs all her subsequent interactions with him about the overdue rent (Bush and Folger, 1994).

What is the intent of the intervenor? A Gestalt practitioner might say it is to support the development of good "contact" between the disputing 
parties. Contact means a meaningful exchange between the two parties: seeing another's point of view and sympathizing, if not agreeing with it; viewing one's opponent as a human being with feelings, values, and needs as valid as one's own; or reminding disputants of previously good or trustworthy relations they may have had with each other. In short, contact means a shift (in feelings, opinions, and perceptions), however minor, in the parties' orientation to the dispute and to each other.

Finally, a relevant hallmark of the Gestalt orientation is clarity of intent on the part of the intervenor and awareness of oneself as a part of the system (disputants plus mediator become a system distinct from the disputants themselves as a two-person system). For whom (or what) am I in service? My own ego needs, my own moral values, the court system? Gestalt theory emphasizes that intervenors must be aware of their own biases and understand their role in the dynamic. It is not enough to limit mediator behavior for fear of mediator bias, which is what Bush and Folger are increasingly doing. We all bring bias to the table; the question is, are we aware of our bias, and how does awareness inform our work? Gestalt is one of many theories that set a firm basis for the efficacy of transformative mediation, but in particular it presents a unifying theory, instead of dialectic, for reflective practice.

\section{Conclusion}

Bush and Folger have done a great service in initiating a conversation about the role of mediation in our society. Their position is provocative: moral growth as the ultimate objective of mediation. They also propose a compelling methodology for mediators. However, they are misguided owing to the same moral pitfalls they assign to results-focused mediation: the values of the mediator trump the disputants' values. Moral imperative is an "objective" just as resolution or settlement is. Ironically, the techniques Bush and Folger advocate achieve the end they desire, without the imposition of a moral imperative.

\section{References}

Antes, J., Folger, J., and Della Noce, D. "Transforming Conflict Interactions in the Workplace: Documented Effects of the USPS REDRESS Program." Hofstra Law and Employment Journal, 2001, 18 (2), 429-467.

Argyris, C., and Schön, D. Organizational Learning: A Theory of Action Perspective. Reading, Mass.: Addison-Wesley, 1978. 
Benjamin, R. "Mediators as Peacemakers: The Revenge Effect." 2001. (www.mediate.com)

Benjamin, R. “The Problem with 'Peace': The Art of William Kentridge.” Unpublished paper, 2003.

Bush, R. B. “'What Do We Need a Mediator For?': Mediation's Value-Added for Negotiators." Ohio State Journal on Dispute Resolution, 1996, 12 (1), 1-36.

Bush, R. B. "Two Pictures of the Future: ADR in the New Millennium." Keynote Address to the New Jersey Statewide Conference on ADR, June 1999.

Bush, R. B. "Substituting Mediation for Arbitration: The Growing Market for Evaluative Mediation, and What It Means for the ADR Field." Pepperdine Dispute Resolution Law Journal, 2002, 3, 111-137.

Bush, R.A.B., "Handling Workplace Conflict: Why Transformative Mediation." Hofstra Labor and Employment Law Journal, 2001, 18 (2), 367-373.

Bush, R.A.B., and Folger, J. P. The Promise of Mediation. San Francisco: Jossey-Bass, 1994.

Bush, R.A.B., and Pope, S. G. "Changing the Quality of Conflict Interaction: The Principles and Practice of Transformative Mediation." Pepperdine Dispute Resolution Law Journal, 2002, 3, 67-96.

Charbonneau, P. "How Practical Is Theory?" In J. Folger and R.A.B. Bush (ed.), Designing Mediation: Approaches to Training and Practice with the Transformative Framework. New York: Institute for the Study of Conflict Transformation, 2001.

Della Noce, D. "Choosing to Make Choices for the Mediation Field." Keynote Address to the Iowa Association of Dispute Resolution, May 1998.

Della Noce, D. J., Bush, R.A.B., and Folger, J. P. "Clarifying the Theoretical Underpinnings for Practice and Policy." Pepperdine Dispute Resolution Law Journal, 2002, 3 (1), 39-74.

Doyle, K. "Transformative Mediation: Confessions of a Facilitative Mediator and Civil Litigator with Evaluative Tendencies.” Paper presented at the Practical Approaches to Appropriate Dispute Resolution Conference, Vancouver, B.C., Mar. 2002.

Enright, J. "An Introduction to Gestalt Techniques." In J. Fagan (ed.), Gestalt Therapy Now. New York: HarperCollins, 1970.

Folger, J. "'Mediation Goes Mainstream': Taking the Conference Theme Challenge." Pepperdine Dispute Resolution Law Journal, 2002, 3 (1), 1-10.

Folger, J., and Bush, R.A.B. "Constructing the World We Want." Plenary Address at the Interaction/Network for Conflict Resolution (Canada) Conference, May 1996 .

Folger, J., and Bush, R.A.B. "Transformative Mediation and Third Party Intervention: Ten Hallmarks of a Transformative Approach to Practice.” Mediation Quarterly, 1996b, 13 (4), 263-278.

Hallberlin, C. J. "Addressing the 'REDRESS': Testimony Before the House Government Reform Subcommittee on Civil Service.” Mar. 29, 2000. 
Hallberlin, C. J. “Transforming Workplace Culture Through Mediation: Lessons Learned from Swimming Upstream." Hofstra Labor and Employment Law Journal, 2001, 18 (2), 375-383.

Kegan, R. The Evolving Self: The Problems and Process of Human Development. Cambridge, Mass.: Harvard University Press, 1982.

Kegan, R. In Over Our Heads. Cambridge, Mass.: Harvard University Press, 1994. Kelly, T. "A Somewhat Critical Analysis of the Transformative Model of Mediation." Portland, Oreg.: Department of Conflict Resolution, Portland State University, 2000.

Köhler, W. Gestalt Psychology. New York: Liveright, 1947.

Lande, J. "How Will Lawyering and Mediation Practices Transform Each Other?" Florida State University Law Review, 1997, 24, 839-926.

Latner, J. "The Theory of Gestalt Therapy." In E. Nevis (ed.), Gestalt Therapy: Perspectives and Applications. Cambridge, Mass.: Gestalt Press, 2000.

Levin, M. S. "The Propriety of Evaluative Mediation: Concerns About the Nature and Quality of an Evaluative Opinion." Ohio State Journal on Dispute Resolution, 2001, 16, 267.

Lewin, K. Resolving Social Conflicts: Selected Papers on Group Dynamics. New York: HarperCollins, 1948.

Nabatchi, T., and Bingham, L. "Transformative Mediation in the USPS REDRESS Program: Observations of ADR Specialists." Hofstra Labor and Employment Law Journal, 2001, 18 (2), 399-427.

Schein, E. Process Consultation. Reading, Mass.: Addison-Wesley, 1987.

Seul, J. "How Transformative Is Transformative Mediation?: A ConstructiveDevelopmental Assessment." Ohio State Journal on Dispute Resolution, 1999, 15 (1), 135-172.

Williams, M. “'Can't I Get No Satisfaction?' Thoughts on the Promise of Mediation." Mediation Quarterly, 1996, 15 (2), 143-154.

Lisa P. Gaynier is an organizational effectiveness consultant, leadership coach, and mediator. She chairs the board of the Cleveland Mediation Center. 